\title{
Anogenital Condyloma: Epidemiological, Clinical, Therapeutic and Evolutionary Aspects of 74 Cases in Benin
}

\author{
F. Akpadjan 1*, C. A. Attinsounon ${ }^{2}$, H. Adegbidi' ${ }^{1}$ C. Koudoukpo ${ }^{3}$, B. Degboe ${ }^{1}$, N. Agbessi3 ${ }^{3}$, \\ F. Atadokpede ${ }^{1}$
}

${ }^{1}$ Dermatology-Venerology, Faculty of Health Sciences of Cotonou, University of Abomey-Calavi, Benin

${ }^{2}$ Infectiology, Faculty of Medicine of Parakou, University of Parakou, Benin

${ }^{3}$ Dermatologie-Venerology, Faculty of Medicine, University of Parakou, Benin

Email: ^barfice@yahoo.fr

How to cite this paper: Akpadjan, F., Attinsounon, C.A., Adegbidi, H., Koudoukpo, C., Degboe, B., Agbessi, N. and Atadokpede, F. (2017) Anogenital Condyloma: Epidemiological, Clinical, Therapeutic and Evolutionary Aspects of 74 Cases in Benin. Journal of Cosmetics, Dermatological Sciences and Applications, 7, 221-228. https://doi.org/10.4236/jcdsa.2017.73021

Received: August 23, 2017

Accepted: September 16, 2017

Published: September 19, 2017

Copyright $\odot 2017$ by authors and Scientific Research Publishing Inc. This work is licensed under the Creative Commons Attribution International License (CC BY 4.0).

http://creativecommons.org/licenses/by/4.0/

\begin{abstract}
The aim of this study was to study the epidemiological, clinical, therapeutic and evolutionary aspects of anogenital warts in Benin. A retrospective cohort study was conducted over a 4-year period from January $1^{\text {st }}, 2013$ to December $31^{\text {st }}, 2016$ at the Dermatology-Venerology Clinic of Cotonou. A total of 74 patients, including 67 men and middle aged $35.1 \pm 10.3$ years, were received for anogenital condyloma during the study period, accounting for $2.1 \%$ of the total and $28.2 \%$ of patients were received for sexually transmitted infection. The most common clinical form was acuminated condyloma (61 cases; 82.4\%). HIV serology was positive in 12 patients (16.2\%). Therapeutically, the use of electrocoagulation was systematic in $80 \%$ of cases. The evolvement is noticeable when $37 \%$ of the cases were recidivated and the rate of loss of sight after the first consultation was $60.8 \%$. Early diagnosis and improvement of the technical platform will help to improve the quality of care for these patients.
\end{abstract}

\section{Keywords}

Anogenital Condyloma, Benin, West Africa

\section{Introduction}

Anogenital condylomas are among the most frequent sexually transmitted infections (STIs) [1]. These benign lesions of infectious origin are caused by several serotypes of human papillomaviruses (HPV). The prevalence of these STIs is about $1 \%$ in industrialized countries and their incidence is increasing worldwide. Although benign, these lesions can have a significant psychological impact on patients and have a significant financial impact on society [2]. HPV transmission 
occurs mostly during first sexual intercourse, but the vast majority of patients eliminate the virus after a few months. The infection progresses in latent form in less than $10 \%$ of cases (asymptomatic carriage). Only $1 \%$ of patients will develop genital HPV lesions. Transmission is predominantly sexual [3] [4]. The risk of association of external condylomas with cervical or anal lesions imposes an assessment of the extent of HPV infection. This assessment consists in looking for other locations in the patient and his partners depending on the context and the sexual practices. The findings should be broadened to the systematic search for other STIs such as HIV infection, viral hepatitis B and C according to context, syphilis, genital herpes, chancroid, gonorrhea and chlamydia [5] [6]. Therapeutically, three types of therapeutic methods were recently published in the annals of dermatology and venereology of October 2016 by Bouscarat et al. [7]. These include chemical treatments (podophyllotoxin, 5 fluorouracil, podophyllin, trichloroacetic acid), immunomodulators (imiquimod) and destructive or ablative physical treatments (cryotherapy, laser, electrosurgery, or surgical excision). But all these treatments still have a recurrence rate of around $30 \%$.

In Benin, genital infections are generally considered taboo. The fear of stigmatization exposes patients to the late use of care with the risk of extension or even worsening of the lesions. Genital warts are sometimes referred to as bewitchment which leads to the almost systematic use of traditional medicine more delaying medical consultation. It is in this context that we conduct this first study which aim is to assess the different aspects (epidemiological, clinical, therapeutic and evolutionary) of anogenital condylomas.

\section{Materials and Methods}

This was a retrospective cohort study of all patients seen in specialized consultation at the Dermatology-Venerology Clinic of Cotonou during the 4-year period from January $1^{\text {st }}, 2013$ to December $31^{\text {st }}, 2016$.

The diagnosis of condyloma was made by doctors specialists in dermatology and venereology based on the elements of the clinical examination. This examination excluded patients seen for non-condylomatous anogenital lesions, such as the pearly penile papules, mollusca pendula, mollusca contagiosa and scrotal calcinosis.

A survey sheet was prepared for this purpose and made it possible to record the various data needed for the study as they were needed. These were the demographic data (age, sex, occupation, provenance), clinical data (location of lesions, their clinical aspects), paraclinic data (Syphilis, HIV, HVB and other STIs), therapeutic and progressive (healing, recurrence, lost view).

The different data collected were entered in the Excel software and analyzed by the Epi Info software version 3.5.1.

\section{Results}

\subsection{From the Epidemiological Point of View}

At the end of this study, 74 patients had been diagnosed for a condyloma out of 
a total number of 3553 patients received during the study period, ie a prevalence of $2.1 \%$. The relative prevalence was $28.2 \%$ to the 262 patients diagnosed for an STI of any category. The middle age of the patients was $35.1 \pm 10.3$ years and the median age was 33 years with extremes of 22 years and 68 years. The sex ratio was 9.6 (or 67 men for 7 women). There were 42 civil servants representing 57\% of the patients followed 17 artisans and workers (23\%), and 15 traders or ressellers (20\%). Thirty-nine patients (52.7\%) had higher education, 21 patients (28.4\%) had secondary education and 14 patients (18.9\%) had left primary school. Patients were from Cotonou (36\% or $48.6 \%$ ), Abomey-Calavi (22 or $29.7 \%$ ), Porto-Novo (13\% or $17.6 \%)$, Allada ( $2 \%$ or $2.7 \%$ ) and Lokossa (1.4\%).

\subsection{From the Clinical and Paraclinical Point of View}

The lesions were in the external genital organs (glans, penis, urethra, vulva) in $70 \%$ of the cases followed by inguinal folds and scrotum (8\%) and anus and anal margin (3\%). In $19 \%$ of the cases, the lesions had a multiple localization. According to the clinical form, 61 cases (or 82.4\%) of acuminated condyloma (Figure 1), 8 cases (or 10.8\%) of papular condylomas (Figure 2) and 5 cases (or $6.8 \%$ ) of giant condylomas (Figure 3 and Figure 4 ).

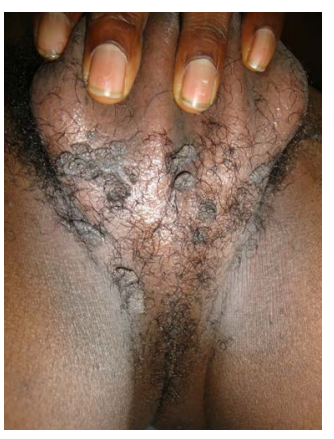

Figure 1. Acuminated condyloma of inguinal folds and scrotum in a 30-year-old man received at the dermatology-venereology clinic of Cotonou in July 2014.

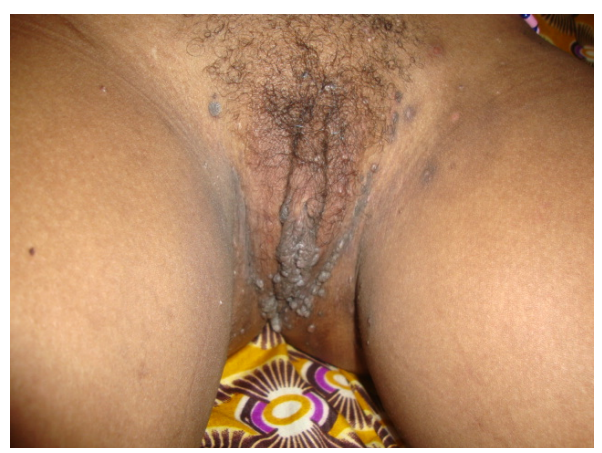

Figure 2. Vulvar papular condyloma in a 32 -year-old woman received at the dermatology-venereology clinic of Cotonou in January 2015. 


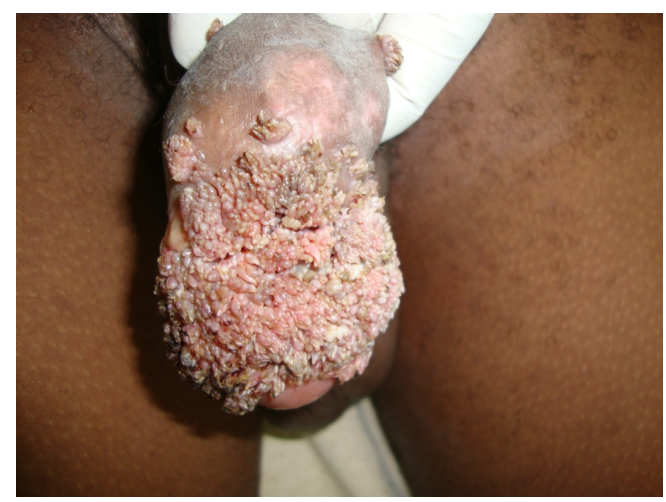

Figure 3. Giant condyloma of the glans in a 40-year-old HIV-positive man, received at the dermatology-venereology clinic of Cotonou in January 2013.

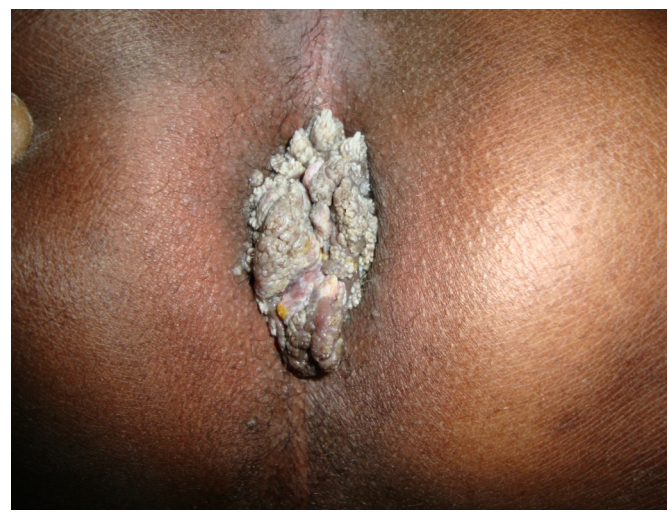

Figure 4. Anal giant condyloma in a heterosexual HIV-positive man, aged 45, received at the dermatology-venereology clinic of Cotonou in February 20.

A combination of two or three STIs was observed in 30 patients (40.5\%). There were two cases $(2.70 \%)$ of genital herpes, one case $(1.35 \%)$ of syphilis, one case $(1.35 \%)$ of chlamydia, two cases $(2.70 \%)$ of scabiosis and 13 cases (17.56\%) of genital candidiasis. HIV serology was positive in 12 patients or $16.2 \%$ of cases.

\subsection{From the Therapeutic and Evolutionary Point of View}

At the first consultation, 69 patients $(93.2 \%)$ received treatment. Fifty-nine patients (79.7\%) received electrocoagulation. In 33 patients (44.6\%), electrocoagulation was associated with interferon alpha. Ten patients $(13.5 \%)$ were treated with low-dose of interferon alpha and podophylotoxin.

The five patients $(6.8 \%)$ who were not treated at the first consultation for lack of financial means were lost to follow-up. Of the 69 patients treated, 40 (or 58\%) were lost to follow-up after the first consultation, 18 were cured $(26.1 \%)$ after an average follow-up period of 02 years and 11 (or 15.9\%) recidivated after an average of three months, requiring electrocoagulation with a favorable evolvement. 


\section{Discussion}

\subsection{On the Epidemiological Level}

Human papillomavirus infections are the most common STIs in the world. Our study agrees in the same direction. Only $5 \%$ of the world population has clinical lesions. The latent form represents $25 \%$ of young people under 25 years old. The prevalence of papillomavirus infections is increasing in all countries [7].

In our study, the overall prevalence of condylomas was $2.08 \%$. It is $1 \%$ in Western countries. The majority of patients were men. This result agrees with that of Mahé and al [8]. Indeed, the latter also found that men represented the population mostly taken in charge by dermatologists. In addition, they noted that female dermatologists had a more readily mixed clintele, whereas male dermatologists saw almost exclusively men. In contrast, Faye and al. [9] in Mali rated 106 women for 43 men, a sex ratio of 0.40 .

The middle age of the patients was 35 years, which is in agreement with the data of the literature. Lukasiewicz and al. [10], that found an average age of 31 years.

\subsection{On the Clinical Level}

The diagnosis of condylomas is mostly clinical [7]; therefore no paraclinical examination is required most of the time except in rare cases where histopathological examination is indispensable.

The localizations and clinical forms of the lesions observed in our patients are in agreement with the literature which proves that the condylomas can be macular, papular or acuminate, even giant; They can sit on the vulva, the pubis, the glans, the balano-genital groove, the rod, the scrotum, the inguinal folds, inter-gluteal folds, the anal margin; as well as several seats can be found in the same patient [5] [7]. It is noted that the longer the consultation period, the more extensive or diffuse the lesions are.

Retroviral and syphilitic serology were negative in the majority of patients; which also explains the low number of giant condylomas observed in the latter on the one hand and the recidivism rate in agreement with the data from the literature. Because immunosuppressed and HIV-positive patients are known to have a high risk of HPV infection [11] [12], with more exuberant and profuse forms of condyloma, and are also prone to therapeutic failures and recurrences.

\subsection{On the Therapeutical Level}

There is no effective antiviral treatment for condylomas. The objective is the disappearance of visible lesions. The treatment is based on a multidisciplinary collaboration (dermatologists, gynecologists, urologists, proctologists). Patient information before treatment prevents confusion (HPV/cancer, viral infection/disease).

According to the recommendations of Bouscarat and al. [7], published in the annals of dermatology and venereology of October 2016, there are three types of 
therapeutic methods: chemical treatments (self-applied cytotoxic: podophyllotoxin, 5 fluorouracil; or non self-applied: podophyllin, Trichloroacetic acid), immunomodulator treatment (Imiquimod), and destructive or ablative physical treatments (cryotherapy, laser, electrosurgery, or surgical excision).

But other therapeutic methods are also proposed in the literature such as: dynamic phototherapy combined with other destructive modalities that could increase the cure rate of genital warts. The quadrivalent vaccine against HPV 6, 11, 16,18 has also been proposed to reduce the incidence of warts in the Western world [13].

Hemper and al. treated a case of perineal giant condyloma by a heavy surgery with flaps of reconstruction and colostomy [14].

Cidofovir intravenous (IV) is also an important therapeutic option in the treatment of severe or recurrent HPV infections, particularly in immunosuppressed patients [15].

But unfortunately in Benin, our therapeutic arsenal is very limited. Our patients were treated mainly by electrocoagulation. Low-dose interferon alpha was used only as an adjuvant, and podophylotoxin alone was only a standby treatment in the latter.

\subsection{On the Evolutionary Level}

Only 29 patients (39.2\%) had been reviewed after treatment and 58\% were lost to follow-up at the first control visit. This significant rate of loss of following-up could be justified either by a satisfactory evolution of the treatment with the absence of recurrence. Nevertheless, we recorded $15.9 \%$ of recidivism. This apparently low rate could be underestimated by the large number of people lost to follow-up. Only an active search for these people could edify us on their becoming and the real evolution of their disease. In the literature, all treatments have a failure rate of at least $30 \%$ and high recurrence rates at 3 months. [7] This rate of recurrence is also identical whatever the method used (about 30\%), considering the possibility of asymptomatic viral infection [16].

\section{Conclusion}

This first study conducted in specialized consultation shows a relatively low prevalence of anogenital condylomas among consultations in general dermatology and venereology in particular. But this rate can be underestimated by the inaccessibility of specialized care to the majority of the population for financial reasons on the one hand, but also the systematic use of traditional medicine and the fear of stigmatization on the other hand. Improving the diagnosis and management of this affection in Benin will involve educating the population, sensitizing general practitioners and all health workers to ensure proper referral of patients as soon as the lesions appear. The availability of modern means of medical and technical management of condylomas would also considerably reduce the relatively high recidivism rate in our context. 


\section{Conflict of Interest}

None.

\section{References}

[1] Simms, I. and Fairley, C.K. (1997) Epidemiology of Genital Warts in England and Wales: 1971 to 1994. Sexually Transmitted Infections, 73, 365-367. https://doi.org/10.1136/sti.73.5.365

[2] Chanal, J., Fouere, S., Yassir-Oria, F., Spenatto, N., Bouscarat, F. and Picot, E. (2016) CONDYDAV: Multicentre Observational Study of Patients with Condylomas in Venereal Anesthesia Clinics in France. Annales De Dermatologie Et De Venereologie, 143, 675-681. https://doi.org/10.1016/j.annder.2016.05.013

[3] Cedef (2015) Item 158 - EU 6 Sexually Transmitted Infections. Annales De Dermatologie Et De Venereologie, 142, S101-S114.

[4] Oriel, J.D. (1971) Natural History of Genital Warts. The British Journal of Venereal Diseases, 47, 1-13. https://doi.org/10.1136/sti.47.1.1

[5] Bouscarat, F. and Mahe, V.D. (2002) External Condylomas. Annales De Dermatologie Et De Venereologie, 129, 1013-1022.

[6] Leonard, B., Kridelka, F., Delbecque, K., Goffin, F., Demoulin, S. and Doyen, J. (2014) A Clinical and Pathological Overview of Vulvar Condyloma Acuminatum, Intraepithelial Neoplasia, and Squamous Cell Carcinoma. BioMed Research International, 2014, 1-11. https://doi.org/10.1155/2014/480573

[7] Bouscarat, F., Pelletier, F., Fouere, S., Janier, M., Bertolloti, A. and Aubin, F. (2016) External Genital Warts (Condyloma). Annales De Dermatologie Et De Venereologie, 143, 741-745. https://doi.org/10.1016/j.annder.2016.09.013

[8] Mahe, E., Descamps,V. and Bouscarat, F. (2002) Management of External Anogenital Condylomas by Dermatologists: Results of a National Survey. Annales De Dermatologie Et De Venereologie, 129, 997-1002.

[9] Faye, O., Kone, A., Dicko, A., Berthe, S., N’Diaye, H.T., Traore, P. and Coulibaly, S.K. (2013) Genital Warts: Study of 149 Cases. Annales De Dermatologie Et De Venereologie, 143.

[10] Lukasiewicz, E. and Aractingi, S. (2002) Incidence and Management of External Condyloma Acuminata in General Practice. Annales De Dermatologie Et De Venereologie, 129, 991-996.

[11] Werner, R.N., Westfechtel, L., Dressler, C. and Nast, A. (2017) Anogenital Warts and Other HPV-Associated Anogenital Lesions in the HIV-Positive Patient: A Systematic Review and Meta-Analysis of the Efficacy and Safety of Interventions Assessed in Controlled Clinical Trials. Sexually Transmitted Infections, 1-8. https://doi.org/10.1136/sextrans-2016-053035

[12] Voltz, J.-M., Drobacheff, C., Derancourt, C., Coumes-Marquet, S. and Mougin, C. (1999) Anogenital Papillomavirus Lesions in 121 HIV-Positive Men Clinical, Histological, Viral, and Evolutional Studies. Annales De Dermatologie Et De Venereologie, 126, 424-429.

[13] Dunn, J. and Koo, J. (2013) Update on the Treatment of Genital Warts. Dermatology Online Journal, 19, 1-19.

[14] Hemper, E., Wittau, M., Lemke, J., Kornmann, M. and Henne-Bruns, D. (2016) Management of a Giant Perineal Condylomata Acuminata Case Report. GMS Interdiscip, 5, 1-5. 
[15] Blaizot, R., Biscay, P., Guillet, S., Dutkiewicz, A.-S., Pham-Ledard, A.L. and Beylot-Barry, M. (2015) Effectiveness of Intravenous Cidofovir for Ano-Genital Warts in a Context of Multifactorial Immunosuppression. Annales De Dermatologie Et De Venereologie, 142, S615-S616.

[16] Aubin, F., Pretet, J.-L., Mougin, C. and Riethmuller, D. (2007) Human Papillomavirus Infection. Annales De Dermatologie Et De Venereologie, 134, 94-99.

Submit or recommend next manuscript to SCIRP and we will provide best service for you:

Accepting pre-submission inquiries through Email, Facebook, LinkedIn, Twitter, etc. A wide selection of journals (inclusive of 9 subjects, more than 200 journals) Providing 24-hour high-quality service User-friendly online submission system Fair and swift peer-review system Efficient typesetting and proofreading procedure Display of the result of downloads and visits, as well as the number of cited articles Maximum dissemination of your research work

Submit your manuscript at: http://papersubmission.scirp.org/ Or contact jcdsa@scirp.org 